\title{
ОСНОВНЫЕ НАПРАВЛЕНИЯ РАЗВИТИЯ ПЕРИНАТАЛЬНОЙ МЕДИЦИНЫ
}

$\Pi$ еринатология как наука возникла в середине прошлого столетия и параллельно с нарастающим техническим и технологическим прогрессом за 60 лет стремительно охватила широкий спектр теоретических и клинических направлений. Пристальное внимание к перинатологии за последние годы возросло в связи с необходимостью поиска способов, позволяющих улучшить демографическую ситуацию, приостановить тенденции роста числа новорожденных с осложненным течением неонатальной адаптации [4].

На сегодняшний день основными разделами перинатальной медицины являются: перинатальная патология, перинатальная биохимия, перинатальная фрармакология, перинатальная эндокринология, психология, генетика и т.д.

Научный поиск в перинатологии на разных этапах ее развития определялся проблемами, стоящими перед всем человечеством: снижение перинатальной заболеваемости, смертности, а также изучение отдаленных последствий перинатальных осложнений; снижение перинатальной смертности недоношенных детей.

В этой связи сегодня перинатологи занимаются научными исследованиями в области:

ф физиологии и патологии эмбриона, плода и новорожденного начиная с момента оплодотворения;

изучения процессов эмбриогенеза и врожденных пороков развития;

определения повреждающих фракторов окружающей среды на здоровье матери и ее ребенка;

изучения системы мать-плацента-плод;

изучения иммуноконфликтной беременности.

Внедрение новейших современных перинатальных технологий возможно только на принципах доказательной медицины. Это позволит четко определить наиболее эффективные технологии, рассчитать экономическую составляющую их внедрения, рекомендовать включение данных технологий в формирование политики здравоохранения с учетом имеющейся в каждой стране социальной и медицинской инфраструктуры [2, 3].

На сегодняшний день уровень развития перинатальной медицины, в т.ч. акушерства и гинекологии, неонатологии, медицинской генетики, педиатрии определяет необходимость введения нового перинатального здоровья, отражающего в первую очередь состояние здоровья ребенка.
K примеру, в странах Евросоюза определяется индекс здоровья плода, который необходимо использовать в качестве основы для установления уровня перинатального здоровья интегрально с такими маркерами, как демедикализация беременности и родов, физиологическое течение родов, ранний неограниченный контакт ребенка с матерью, грудное вскармливание сразу при рождении ребенка, физиологическая адаптация раннего неонатального периода.

Еще в 1998 г. Европейское региональное бюро ВОЗ приняло концепцию «Здоровье для всех в XXI веке», в которой выделены три стратегических направления. Конечными их целями должно стать обеспечение здорового старта жизни ребенка:

эфффективная перинатальная помощь;

с сохранение здоровья и развития детей первых 5 лет жизни;

(3 соблюдение прав ребенка.

На сегодняшний день принципы эффективной перинатальной помощи предусматривают:

определение динамического перинатального риска у данной женщины;

s регионализацию перинатальной помощи;

б физиологическое ведение родов с минимальным вмешательством;

демедикализацию родов;

э участие близкого человека (партнера) в родах;

s ранний неограниченный контакт матери и ребенка;

з раннее грудное вскармливание;

э эффективную первичную реанимацию.

Итогом создания оптимальной системы организации медицинской помощи новорожденным и детям раннего возраста должно быть внедрение новейших современных технологий в акушерстве, неонатологии и педиатрии, основанных на принципах доказательной медицины, а также повышение квалификации врачей и среднего медицинского персонала, что позволило позитивно влиять на показатели неонатальной и младенческой заболеваемости и смертности.

Следует признать, что антенатальная диагностика является одной из наиболее ресурсоемких отраслей медицины. Вместе с тем необходимо учесть, что стоимость лечения, медицинской и социальной реабилитации, а также пожизненного содержания больного с врожденной патологией в 100-1000 раз превышает затраты на антенатальную диагностику,

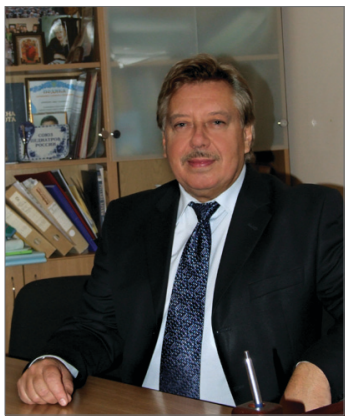

Ю.Г. АНТИПКИн

академик НАМН Украины, д.мед.н., директор Института педиатрии, акушерства и гинекологии НАМН Украины

\section{Ю.В. ДАВЫДОВА}

д.мед.н., заведующая отделением акушерских проблем экстрагенитальной патологии

Института педиатрии, акушерства и гинекологии НАМН Украины 


\section{ТАБЛИЦА 1}

Принципы диагностики

Скрининговые

Верифицирующие

ТАБЛИЦА 1

ПРИНЦИПЫ АНТЕНАТАЛЬНОЙ ДИАГНОСТИКИ ВРОЖДЕННЫХ ПОРОКОВ РАЗВИТИЯ

\section{Направленность}

Методы

Позволяют выделить группу Оценка анамнестических данных высокого риска Ультразвуковая диагностика Определение биохимических маркеров наследственной патологии

Позволяют подтвердить или Цитогенетический, молекулярноисключить предваритель- генетический, биохимический, миный диагноз (исследуются кробиологический, сероиммунологиклетки и ткани плода) ческий анализы

профилактику и коррекцию патологии плода. Следует подчеркнуть, что в результате технического прогресса и с появлением все более совершенной ультразвуковой аппаратуры, лучевых методов диагностики, с внедрением инвазивных способов получения фетальных тканей, применением методов молекулярной биологии и цитогенетики антенатальная диагностика стала намного более технологичной, и это диктует решение новых проблем.

По материалам ВО3 [6], около 4-5\% всех детей появляются на свет с той или иной врожденной патологией. Так, среди 1000 родившихся живыми у 10 детей выявляются моногенные болезни, у 6 - хромосомные, у 20 - врожденные пороки развития иного, в т.ч. инфекционного, происхождения, у 10 детей - болезни с выраженной наследственной предрасположенностью.

В этом аспекте необходимо отметить следующее: основные принципы методологии диагностики определены глобально и в мире, и в нашей стране. На повестке дня - реализация использования разработанных методов оценки нарушений эмбриона и плода для всех женщин, обратившихся за антенатальным наблюдением. Все, что достигнуто в научно-исследовательских центрах, университетских клиниках, необходимо сделать доступным для любой семьи, планирующей рождение ребенка.

В нашей стране стремление к реализации Национального проекта «Новая жизнь - новое качество охраны материнства и детства» по инициативе Президента страны объединило усилия не только профильных специалистов Администрации Президента, Министерства здравоохранения, Национальной академии медицинских наук, но и неправительственных организаций, представительств международных организаций и фондов, средств массовой информации, общественных организаций и фондов Украины.

Так, принципы антенатальной диагностики врожденных пороков развития научно обоснованы и разработаны в ГУ «Институт педиатрии, акушерства и гинекологи НАМН Украины» под руководством академика НАМН и НАН Украины Е.М. Лукьяновой и профессора И.Ю. Гордиенко, а сегодня они внедряются по всей территории нашей страны (табл. 1).

Проектом «Новая жизнь» предусмотрено создание региональных перинатальных центров III уровня с отделениями патологии ранних сроков гестации, обеспечение всех центров современными аппаратами ультразвуковой диагностики, подготовка специалистов экспертного уровня. На ГУ «Институт педиатрии, акушерства и гинекологии НАМН Украины» возложена функция верификации диагноза в наиболее сложных случаях, с использованием современных методов генетической диагностики.

Следующим направлением современной перинатальной медицины является разработка мероприятий по профилактике преждевременных родов и минимизации последствий недоношенности для матери, плода и новорожденного [1]. Принимая во внимание то, что частота преждевременных родов не имеет тенденции к снижению (в США ежегодно распространенность преждевременных родов составляет 12\%, при этом расходы на преодоление последствий недоношенности составляют 26 млрд дол.), направление научного поиска в нашем институте в этом аспекте охватывает определение иммунологических, генетических, инфекционных фракторов, которые могут стать триггерным механизмом начала преждевременных родов. Кроме того, изучается эфффективность технологий выхаживания детей, родившихся с низкой и экстремально низкой массой тела для разработки рекомендаций и внедрения их в практику региональных перинатальных центров.

Проектом «Новая жизнь» в данном направлении также предусмотрено обеспечение всех региональных перинатальных центров необходимой аппаратурой для жизнеобеспечения и выхаживания недоношенных и глубоко недоношенных детей с использованием принципов активного вовлечения родителей ребенка к процессу реабилитации, принимая во внимание технологию «мама-кенгуру».

Сегодня ни дальнейшее развитие перинатологии как науки, ни перинатальной медицины как практического воплощения научных достижений невозможно без развития фетальной хирургии, совершенствования внутриматочных методов коррекции врожденной патологии $[4,5]$.

В экономически развитых странах мира в настоящее время разработаны следующие показания для фетальной хирургии:

1. Абляция сосудистых анастомозов при двойне с акардиальным плодом.

2. Лазерная абляция сосудистых анастомозов при раннем, тяжелом фрето-фретальном трансфузионном синдроме.

3. Удаление крестцово-копчиковой тератомы.

4. Восстановление менингоцеле.

5. Резекция измененной легочной ткани или установление торако-амниотического шунта при наследственной кистозной аденоматоидной мальформации, внедолевой легочной секвестрации. 
6. Пузырно-амниотическое шунтирование как лечение обструкций мочевыделительного тракта.

На уровне экспериментальных и находящихся в стадии изучения считаются следующие вмешательства:

1. Окклюзия трахеи при врожденной диафрагмальной грыже.

2. Лечение врожденных пороков сердца.

3. Лечение гастрошизиса.

4. Трансплантация стем-клеток.

5. Генная терапия.

В таблице 2 представлены хирургические подходы к восстановлению пороков развития внутриутробно.

На сегодняшний день в нашем институте в отделении медицины плода, врожденных пороков развития (под руководством профрессоров И.Ю. Гордиенко, Т.В. Авраменко, А.К. Слепова) проводится подготовка к выполнению фетоскопических операций, установлено оборудование для технологического обеспечения их проведения, отрабатываются алгоритмы взаимодействия мультидисциплинарной команды.

Особое внимание в современной перинатологии уделяется профрилактике перинатальных осложнений у женщин с тяжелой экстрагенитальной патологией, которой институт занимается десятки лет под руководством професссора Л.Б. Гутман, члена-корреспондента НАМН Украины В.И. Медведя. Так, в институте отработаны стандарты медицинского сопровождения беременных с врожденными и приобретенными пороками сердца, заболеваниями системы гемостаза, сахарным диабетом, заболеваниями щитовидной железы. Внедрение этих стандартов в практику учреждений, обеспечивающих перинатальную помощь разного уровня, позволит снизить материнскую и перинатальную заболеваемость и смертность до среднеевропейского уровня.

С учетом мировых тенденций развития перинатологии необходимо продолжать научный поиск в следующих направлениях:

п перинатальные поражения нервной системы: изучение этиопатогенеза, усовершенствование классифрикации, диагностики, профрилактики, лечения;

у усовершенствование молекулярно-генетических, лабораторных и инструментальных методов диагностики в оценке и прогнозировании состояния плода и новорожденного;

s оптимизация диагностики, лечения и профрилактики перинатальных инфекций;

хирургические методы лечения плода и новорожденного;

просрилактика, диагностика и коррекция гемодинамических нарушений в неонатальном периоде;

бл блжайшие и отдаленные исходы задержки роста плода;

бл блжайшие и отдаленные исходы у детей, родившихся с низкой и экстремально низкой массой тела.

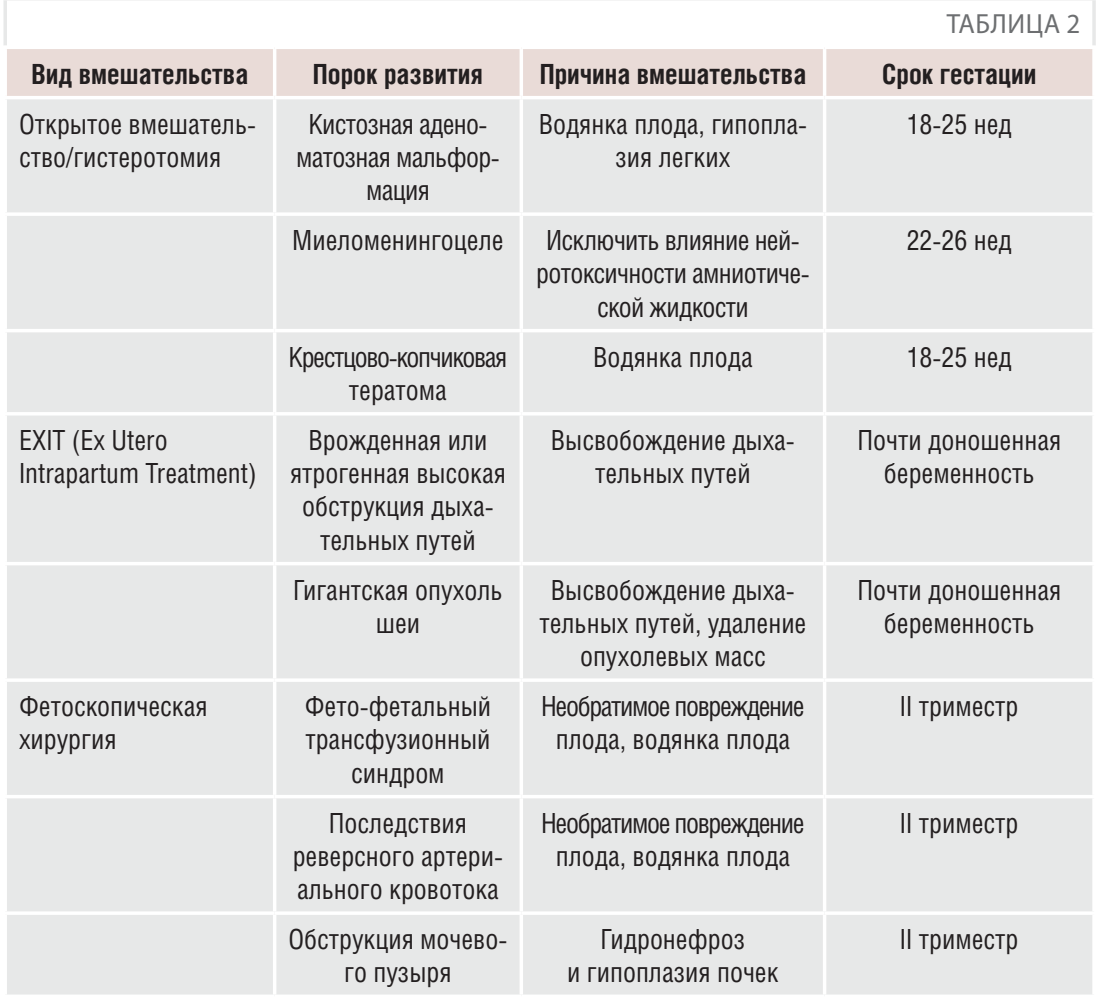

ТАБЛИЦА 2.

Уровень современной медицины позволя- ХирургическиЕ подходы принципов:

координированное проведение высокотехнологичных фундаментальных исследований;

s создание инновационной перинатальной технологии;

оценка эфрфективности технологии в соответствии с положениями доказательной медицины; разработка клинического протокола;

s создание и обучение мультидисциплинарной команды;

внедрение методологии в региональных перинатальных центрах;

аудит качества оказания перинатальной помощи в данных центрах.

Результаты работы в указанных направлениях позволят эффективно реализовать Концепцию развития перинатальной медицины в Украине и будут способствовать достижению Целей развития тысячелетия.

\section{ЛИТЕРАТУРА}

1.Di Renzo G.C., Roura L.C. and the European Association of Perinatal Medicine-Study Group on «Preterm Birth». Guideline for the management of spontaneous preterm labour // J. Perinat. Med. 2006; 34: 359-66.

2. Golombeck K., Ball R.H., Lee H. et al. Maternal morbidity after maternal-fetal surgery // Am. J. Obstet Gynecol. 2006 Mar; 194 (3): 834-9.

3. Hack M., Taylor H.G., Drotar D. et al. Poor predictive validity of the Bayley Scales of Infant Development for cognitive function of extremely low birth weight children at school age//Pediatrics. 2005; 116: 333-41.

4. Sheth S.S. Reduction in mortality needs a bit more than the science of perinatology // Journal of Perinatal Medicine. V. 31, Issue 5, Pages 373-375, June 2005.

5. Maternal-Fetal Surgery Conference, July 16-18, 2000, Bethesda, Maryland. 